\title{
Taking care of business and doing overtime: Teaching research methods in public affairs curricula pre-pandemic and during COVID-19
}

John F. Brennan

Christopher R. Prentice ( $D$ prenticecr@uncw.edu )

Kirsten L. Kinzer

Jeffrey L. Brudney

\section{Research Article}

Keywords: quantitative and research methods, online instruction, public affairs, COVID-19

Posted Date: September 23rd, 2021

DOI: https://doi.org/10.21203/rs.3.rs-930213/v1

License: (c) (i) This work is licensed under a Creative Commons Attribution 4.0 International License.

Read Full License 
Taking care of business and doing overtime: Teaching research methods in public affairs curricula pre-pandemic and during COVID-19

In this research, we sought to better understand important trends and developments in the teaching of quantitative and research methods courses in graduate public affairs programs. We were specifically interested in the following areas related to the teaching of quantitative and research methods: the impact of new technologies on curriculum delivery; the content of courses related to statistical analysis and research design; and the importance of numeracy, ethics, and data visualization. We surveyed quantitative and research methods instructors in graduate public affairs programs using the same survey instrument at two intervals eight years apart and analyzed results from each period sideby-side. Findings indicate some stark differences in the content and delivery of these courses. Given the timing of the second survey - Spring 2021 - findings are considered within the context of the COVID-19 pandemic.

Keywords: quantitative and research methods; online instruction, public affairs, COVID19

\section{Funding}

The authors received no financial support.

\section{Declaration of Conflicting Interests}

The authors declare no potential conflicts of interest. 


\section{Introduction}

Social statistics has long been a cornerstone in graduate public affairs curricula. NASPAA's accreditation standards highlighting the importance of research methods and quantitative analysis certainly contribute to this ubiquity, but faculty are also motivated by the desire to have students gain quantitative skills useful for policy analysis, program evaluation, and decision making (Horne, 2008). The content of quantitative and research methods courses has evolved over the last few decades, coincident with changing technologies, learning goals for students, and workforce needs. Additionally, new instructional technologies are changing the way instructors impart knowledge and skills to students.

In this research, we sought to better understand important trends and developments in the teaching of quantitative and research methods courses in graduate public affairs programs. We were specifically interested in the following areas related to the teaching of quantitative and research methods: the impact of new technologies on curriculum delivery; the content of courses related to statistical analysis and research design; and the importance of numeracy, ethics, and data visualization. We surveyed quantitative and research methods instructors in graduate public affairs programs using the same survey instrument at two intervals eight years apart and analyzed results from each period side-by-side. Findings indicate some stark differences in the content and delivery of these courses. Given the timing of the second survey - Spring 2021 - findings are considered within the context of the COVID-19 pandemic.

In the following section we review the relevant literature and highlight trends in the development of quantitative and research methods courses in graduate public affairs programs. Next, we present our methodology, including sample identification, survey design and dissemination, and statistical methods used for analysis. Finally, we present the noteworthy 
results from the pooled cross-sectional analysis, discuss the implications of these findings for public affairs faculty, and conclude with suggested directions for future research.

\section{Literature Review}

Survey research on the topics covered in quantitative course work in MPA programs began in the late 1970s and a series of three surveys established the field's baseline understanding of which quantitative topics are covered in MPA courses, as well as student backgrounds in statistics and math and the use of computer programs in these courses (Hy, Waugh, and Nelson, 1987; Waugh, Hy, \& Brudney, 1994). A primary focus of these surveys was identifying the quantitative techniques covered in different MPA programs, ranging from descriptive statistics to PERT. Although virtually every MPA program required a quantitative course by 1984, "the types of quantitative techniques taught in graduate programs of public administration var[ied] tremendously. Some programs expose[d] a majority of their students to a wide variety of techniques, while others expose[d] them to only a very few" (Hy et al., 1987, p. 145). Despite this variation in topical coverage, the emphasis in MPA coursework remained on social science statistics rather than management science.

More recently, scholars have suggested that quantitative coursework in public affairs should expand to better prepare students for professional work as public administrators and policy analysts (Horne, 2008). Fitzpatrick (2000) argued that rather than preparing students for $\mathrm{PhD}$ programs, MPA programs should prepare students to complete and apply research in public management and policy decision making. To this end, Fitzpatrick rejected Waugh et al.'s (1994) argument that covering more sophisticated social statistics is the appropriate goal of MPA coursework. Similarly, Caulkins (1999) maintained that management science is more relevant to students seeking professional jobs after graduation (e.g. network modeling, forecasting, and 
simulation). Aristigueta and Raffel (2001) advocated for a "third path" focused on quantitative decision making, drawing from both the research design and management science traditions. Ammons and Williams (2003) considered this question from the perspective of employer needs in the 50 largest American cities and concluded that these entry level budget and program analyst positions require knowledge of basic descriptive statistics and management science rather than the more advanced social science statistics. Despite these arguments, social science statistics and research design remain the focus of quantitative courses in most public affairs programs in part because instructors are trained in this tradition and tend to "teach what they know" (Horne 2008).

This study builds from the larger body of research on the integration of quantitative topics into public affairs education and encompasses two seismic shifts in higher education: the rapid growth in NASPAA accredited programs that offer some or all courses online (Ni, 2013) and the abrupt shift to online learning as a result of the COVID-19 pandemic. The first shift was gradual and mostly voluntary driven by university preferences, student need, and instructor preference. However, the second and more abrupt shift to increased online teaching was imposed by the COVID-19 pandemic as universities increasingly moved courses online starting in Spring 2020. As McDonald (2021, p. 4) notes, "in many ways, the transition provided a referendum about online education. This referendum is worth exploring, as it likely furthered the divide between supporters and opponents to online education. Developing a successful online course is not easy and can take up to a year to complete."

Findings from previous studies that compare online to in-person quantitative and research methods courses in public affairs programs are mixed. In several small studies, scholars found online quantitative methods courses to be superior to in person courses in some ways. Ni (2013) concluded that both the quality and quantity of interaction is higher in online public 
administration research methods courses in comparison to in-person courses covering the same material. Similarly, Harris and Nikitenko (2014) compared online and in-person quantitative methods courses across three cohorts and found that online students performed $28 \%$ higher on writing assignments. They attribute this performance difference to the self-directed learning inherent to online courses. Online courses also expand access to graduate education in public affairs because they provide the flexibility that adult learners need to fit coursework into their lives (Nollenberger, 2015). Conversely, scholars have illuminated a range of ways online courses in public administration do not perform as well as in-person courses, including most notably lower student persistence (Ni, 2013; Moody, 2004). Reduced student motivation and enrollment attrition have also been cited as more persistent issues in online courses when compared to courses taught in-person (Gigliotti, 2016). The abrupt shift online for many instructors and students during COVID-19 likely impact student engagement and learning, but may have also influenced content coverage in quantitative and research methods courses. We explored these possibilities in this study; the next section presents our methods and analytical approach.

\section{Materials and Methods}

Much of what we know about the evolution of quantitative and research methods courses in graduate public affairs programs was built through studies performed at various intervals over the last few decades by scholars loosely replicating prior research in order to elucidate trends. We adopted that tradition of employing similar techniques over time and sought to improve upon it by performing a pooled cross-sectional analysis on data gathered by the research team eight years apart. By maintaining consistency in our instrument and data collection methods, we were able to control for potential methodological variations and improve the comparability of findings from the different collection periods. 


\section{Survey}

Our primary data emanate from surveys distributed eight years apart (spring of 2013 and spring of 2021). The surveys sought information about the content and delivery mode of the graduate quantitative and research methods courses offered by the respondents' programs. The first section of the instrument asked respondents to supply information regarding the format of their methods course - i.e., whether it is offered in-person or online - and whether the move online had influenced student interaction, instructor responsibilities, or student learning. The next four sections of the instrument sought detailed information about course content with one section dedicated to each of the following areas: course topics, numeracy, ethics, and data visualization. The course topics section of our survey is modeled after Hy et al. (1987) and Waugh et al. (1994); however, the latter three sections - numeracy, ethics, and data visualization - are newer contributions.

Respondents were asked to respond to four matrix-style questions (one question for each of the sections) using a 5-point Likert scale corresponding to whether they spent no time to significant time covering each of the items under consideration. For example, respondents were asked whether they spent "none," "a little," "a moderate amount," "a lot," or "a great deal" of class time on the following ethical principles: confidentiality, honesty, objectivity, plagiarism, etc. After data collection, results were recoded and reduced to three categories - i.e., "no time," "some time," or "significant time" - given the low number of counts and unequal variances for some items. Table 1 presents the items respondents were asked to score for each of the four content-specific sections in the survey. Respondents were also afforded the opportunity to enter additional information through free response questions in each of the sections of the survey. 
Our university's policies on human subjects research require Institutional Review Board (IRB) approval before commencing data collection. Hence, we sought and gained IRB approval for our research proposal, survey instrument, methods of communication, and incentive protocol before distributing our survey in 2013 and again before survey distribution in 2021.

\section{Samples}

The study's samples comprised the population of NASPAA members that offer a graduate degree program. We compiled a list of names and contact information for faculty who teach quantitative and research methods courses in the NASPAA member's graduate degree program by perusing college and university webpages. Where it was not possible to ascertain who taught methods courses in the program, we instead collected the program director's name and contact information. Electronic surveys were distributed via email to each of the respondents on our compiled lists $(\mathrm{n}=318$ in 2013 and $\mathrm{n}=301$ in 2021).

The first cross-sectional survey was constructed using SurveyMonkey and disseminated to respondents via email in Spring 2013. The second cross-sectional survey was constructed using Qualtrics and disseminated to respondents via email in Spring 2021. Data collection yielded 167 and 122 usable responses from the first and second survey waves, respectively.

\section{Analysis}

Our analytic approach involved comparing survey data from the two periods. First, we generated frequencies for every variable in 2013 and 2021, and then compared them to determine whether significant differences emerged. Crosstabs were performed for each of the survey items listed in Table 1 to ascertain whether faculty are dedicating more or less time on these concepts over time. Subsequently, we compared means via independent-samples t-tests to determine whether the average overall time spent on numeracy, topics, ethics, and data visualization had 
increased or decreased over time. Finally, we focused on the results from the second survey and analyzed whether COVID-19 influenced the coverage of course content.

\section{Results}

Results from our two cross-sectional surveys indicate faculty are spending less time covering the material listed in Table 1. We present the frequencies and Pearson chi-square statistics for each of the items across the two periods in Tables 2a-e below. Among the numeracy concepts, findings indicate that faculty are dedicating significantly less time to weighted averages and indexes. For example, whereas $42 \%$ of respondents in 2013 indicated that they spent significant time on weighted averages, by 2021 that number dropped to just $25 \%$.

Similarly, whereas only $31 \%$ of respondents indicated spending no time on indexes in 2013 , the number increased to $52 \%$ in 2021 . The other numeracy concepts do not show statistically significant differences across periods, but many items appear to be trending down suggesting less overall coverage. Indeed, the average amount of time dedicated to numeracy concepts did see a statistically significant decline from 2013 to $2021(t(196)=2.45, p=0.02)$.

>>Insert Universal Tables 2a-e here $<<$

Findings for the items listed in the course topics section (Table 2c) of the survey also appear to indicate faculty are dedicating less coverage in 2021 than in 2013. Faculty are spending significantly less time covering quasi-experimental designs, probability distributions, and nonexperimental designs. For example, 52\% of faculty in 2013 indicated they spent significant time covering probability distributions (e.g., normal and student's-t), but that number dropped to $35 \%$ in 2021. Similarly, $24 \%$ of faculty reported spending little to no time on non-experimental designs in 2013, but that number rose to $39 \%$ in 2021. Consistent with the trend in numeracy, 
overall time dedicated to these topics appeared to decline between the two cross-sectional surveys but analyses do not indicate those differences as statistically significant.

Results reported in Table $2 \mathrm{~d}$ show that the ethical concepts under consideration did not show statistically significant differences between periods. The trends indicated in crosstabs and other tests show a generally negative trend, with less time dedicated to many of the individual concepts and for the average amount of time overall. However, unlike the other three sections of the survey these differences do not appear to be significant.

On the other hand, respondents reported spending significantly less time on several data visualization concepts (Table 2e). Results show that faculty dedicate significantly less time covering stem-and-leaf diagrams, histograms, graduated symbol maps, and dot density maps. For example, whereas $56 \%$ of respondents spent some or significant time covering stem-and-leaf diagrams in 2013 , only $33 \%$ of respondents reported similarly in 2021 . The concept that bucks the trend most notably is advanced table design (e.g., crosstabs), where the change appears curvilinear. Respondents in 2021 reported spending significant time or no time at significantly higher rates than their counterparts in 2013. Consistent with the other sections of the survey, the average amount of overall time dedicated to data visualization is lower in 2013 than in 2021. However, unlike with numeracy the observed difference does not appear statistically significant.

\section{Course Delivery and the Impact of COVID-19}

Results from our questions pertaining to the means of course delivery show that significantly more quantitative and research methods courses are being taught online now compared to $2013\left(X^{2}(1, N=275)=82.49, p=0.00\right)$, which may account for some of the changes in course content. Only $27 \%$ of respondents taught methods online in 2013 , but that number climbed to $82 \%$ in 2021 . Faculty also reported that teaching online affected content and 
student engagement. When compared to a traditional face-to-face delivery, faculty in 2021 were significantly more likely to report less student interaction $\left(X^{2}(2, N=126)=13.34, p=0.00\right)$, completing fewer computational exercises $\left(X^{2}(2, N=123)=5.32, p=0.07\right)$, and less instructor feedback on student progress $\left(X^{2}(2, N=126)=5.29, p=0.07\right)$ than their 2013 counterparts.

Some of this variance is likely a consequence of the COVID-19 pandemic. Respondents in both survey waves were asked to report the motivation for teaching methods online, rather than face-to-face, and nearly half of those who answered this question in 2021 indicated in their free response that the pandemic was a factor. In order to explore the extent to which COVID-19 may have influenced course delivery and content, we replicated the analyses performed above and confined our focus to the 2021 survey wave. We created a binary variable that assigned a value of 1 to respondents who mentioned COVID-19 as a motivation for teaching online, and 0 to all others. Faculty who cited the pandemic as a motivator for teaching online reported that compared to face-to-face delivery their online course had significantly less student interaction $\left(X^{2}(2, N=91)=8.10, p=0.02\right)$, fewer computational exercises $\left(X^{2}(2, N=91)=4.95, p=0.08\right)$, more instructor time spent in preparation $\left(X^{2}(2, N=91)=5.39, p=0.07\right)$, more instructor time spent grading $\left(X^{2}(2, N=91)=5.22, p=0.07\right)$, and less overall class attainment of learning objectives $\left(X^{2}(2, N=91)=10.38, p=0.01\right)$.

We also explored whether individuals who noted COVID-19 as a motivation for teaching online responded differently than their counterparts in 2021 to the content-related items listed in Table 1. As expected, some stark differences emerged and those who noted COVID-19 as a motivation reported covering significantly less material. Table 3 below reports only the crosstabs that achieved statistical significance. When the pandemic was a motivator for moving online, those faculty reported spending significantly less time covering numeracy concepts of 
aggregation of data and indexes. They also reported significantly less time on the topics of qualitative methods, sampling, descriptive statistics, probability distributions, hypothesis testing, correlation, linear regression, multiple regression. Ethics and data visualization were likewise affected with faculty citing the pandemic reporting spending significantly less time covering honesty, plagiarism, and time-series line graphs. Taken together, the average amount of time dedicated to data visualization $(t(104)=2.09, p=0.04)$ and course topics $(t(104)=2.78, p=$ 0.01) were significantly lower for the respondents who mentioned COVID-19 as a motivating factor for moving online. Average overall time dedicated to numeracy and ethics concepts also declined, but the observed differences were not statistically significant.

$$
>\text { Insert Table } 3 \text { here }<<
$$

\section{Discussion}

In this research, we sought to better understand trends and developments in the teaching of quantitative and research methods courses in graduate public affairs programs. Findings from our pooled cross-sectional analysis suggest significant differences in the content and modality of these courses over the eight-year period. What we are not able to ascertain from these findings is why these changes emerged and the extent to which they are driven by thoughtful reflection, changes in modality, or disruptions wrought by the COVID-19 pandemic. One would hope instructors are evolving their courses to adapt to changing technologies and workforce needs, but it is unclear from these findings why covering less content would achieve those goals. Future research should explore why instructors are adapting content coverage in these courses.

It is possible that course modality - which is increasingly online - is influencing course content. We know instructors are likely to experience lower student persistence in online classes (McLaren, 2004; Ni, 2013). It is possible that efforts to encourage student persistence is 
influencing how instructors structure methods courses and forcing them to cover less material. Alternatively, instructors may be responding to the needs of different student populations in online versus in-person courses. If online courses include a higher percentage of in-service students who plan to continue their professional careers after graduation, it is possible that instructors have adapted their course material in line with scholarly recommendations (Caulkins, 1999; Aristigueta \& Raffels, 2001; Horne, 2008) to focus more on management science and less on social statistics.

It remains difficult to disentangle the influence of the COVID-19 pandemic on the observed findings. It is possible the statistically significant findings showing less content coverage over time is a temporary bump in the road. Once the disruptive effects of the pandemic are past, perhaps these differences may be less evident. However, one ought to not dismiss too quickly these findings even if they are a consequence of the pandemic. Given path dependence, these practices are entirely likely to persist if not promptly and thoughtfully addressed.

What is clear from the 2021 survey is that instructors who moved their course online in response to the pandemic covered less material and did not achieve the gains in student learning outcomes and interaction seen in previous studies of quantitative and research methods courses in public administration (e.g. Ni, 2003; Harris and Nikitenko 2014). It is possible the disruption and trauma of the pandemic influenced students and instructors alike, and those factors account for the differences we observe.

Undoubtedly, many quantitative and research methods courses will remain online after the pandemic wanes. Therefore, it is important to support instructors who seek to improve student engagement and learning outcomes in the future. Although many universities have resources related to online pedagogy more generally, discipline and subject specific support 
could also be facilitated by NASPAA. The technological tools that encourage student engagement and learning in a quantitative methods course are quite different from those appropriate to other public affairs courses. Therefore, support specifically aimed at instructors of online quantitative courses at NASPAA member schools may be warranted if the trends of decreased topic coverage, student engagement, and lower learning outcomes persists.

\section{Conclusion}

In this article, we explored the impact of new technologies on curriculum delivery; the content of courses related to statistical analysis and research design; and the importance of numeracy, ethics, and data visualization. Findings from surveys sent to quantitative and research methods instructors in graduate public affairs programs eight years apart indicate stark differences in the content and delivery of these courses. It should come as no surprise that significantly more quantitative and research methods courses are taught online in 2021 than in 2013. The unexpected and concerning findings pertain to the significant decline in content coverage in these courses. Our results raise questions that future research might explore, particularly pertaining to why instructors are modifying methods courses to cover less content.

It is vital to know whether this evolution is occurring because instructors are adapting classes based on technological developments and best practices to ensure students are prepared for the workforce, or whether these changes are attributable to other factors. The most optimistic view is that the disruptions of the COVID-19 pandemic forced instructors to quickly prioritize in a difficult environment and content coverage will self-correct when the effects of the pandemic are past. However, it remains possible that the accelerated move to online delivery - hastened and encouraged by university administrators - is influencing course content. According to prior 
research, student persistence is lower in an online environment. Thus, technical classes - e.g., quantitative methods, financial management - may be more difficult to deliver in that medium.

This research relied on insights derived from surveys deployed eight years apart, which offers many advantages over a typical cross-sectional analysis. However, our approach is not without shortcomings. The increased presence of data analytics courses in NASPAA-accredited programs may be influencing what instructors cover in their methods courses. Indeed, one respondent noted that they cover less content in their methods course because they now offer a second statistics and analytics course. In that case, the observed differences are less a function of instructors potentially "watering down" their courses and more about a thoughtful evolution and expansion of what we teach future public and nonprofit professionals. Nonetheless, whereas most programs require a methods course for degree completion, additional statistics and data analytics courses are oftentimes an elective path and not all student may be engaging important content.

A second potential shortcoming of our research may emerge because we neglected to include a relevant item in the survey instrument. We maintained consistency in our instrument and data collection methods to control for potential methodological variations and improve the comparability of findings from the different collection periods. However, much has changed over the eight-year period. For example, one respondent noted that they now incorporate data programming in R, whereas they just used software with dropdowns in 2013. An increased focus on tools such as programming demonstrates a pivot that is responsive to changing workforce needs.

Similar to Horne (2008), we hope this article will stimulate more discussion and thoughtful consideration about what and how we teach quantitative and research methods 
courses in graduate public affairs programs. Our students are current and future public and nonprofit professionals, and it is our responsibility to give them the skills and knowledge they need to be successful in a changing economy. 


\section{References}

Ammons, D. N., \& Williams, W. A. (2003). Developing and applying analytic capabilities in major American cities. Public Administration Quarterly, 27 (3/4), 392-409.

Aristigueta, M. P., \& Raffel, J. A. (2001). Teaching techniques of analysis in the MPA curriculum: Research methods, management science, and "the third path". Journal of Public Affairs Education, 7(3), 161-169.

Caulkins, J. P. (1999). The revolution in management science instruction: Implications for teaching public affairs students. Journal of Public Affairs Education, 5(2), 107-117.

Fitzpatrick, J. (2000). What are our goals in teaching research methods to public administrators?. Journal of Public Affairs Education, 6(3), 173-181.

Gigliotti, R. A. (2016). Institutional identification and sense of community: Analysis of a new online graduate public administration program. Journal of Public Affairs Education, 22(3), 399-414.

Harris, R. A., \& Nikitenko, G. O. (2014). Comparing online with brick and mortar course learning outcomes: An analysis of quantitative methods curriculum in public administration. Teaching Public Administration, 32(1), 95-107.

Horne, C. S. (2008). Teaching what we know: Describing and challenging the neglect of management science methods in MPA programs. Journal of Public Affairs Education, 14(3), 427-438.

Hy, R. J., Waugh, W. L., \& Nelson, P. B. (1987). The future public administrator and quantitative skills. Public Administration Quarterly, 11 (2) 134-149.

McDonald, B. D. (2021). Teaching in uncertain times: The future of public administration education. Teaching Public Administration. Advance online publication. https://doi.org/10.1177/0144739420963154

McLaren, C. H. (2004). A comparison of student persistence and performance in online and classroom business statistics experiences. Decision Sciences Journal of Innovative Education, 2(1), 1-10.

Moody, J. (2004). Distance education: Why are the attrition rates so high?. Quarterly Review of Distance Education, 5(3), 205.

Ni, A. Y. (2013). Comparing the effectiveness of classroom and online learning: Teaching research methods. Journal of Public Affairs Education, 19(2), 199-215.

Nollenberger, K. (2015). Comparing alternative teaching modes in a masters program: Student preferences and perceptions. Journal of Public Affairs Education, 21(1), 101-114. 
Waugh, W. L., Hy, R. J., \& Brudney, J. L. (1994). Quantitative analysis and skill building in public administration graduate education. Public Administration Quarterly, 18 (2), 204222. 


\section{Tables}

Table 1. Survey items for each of the four content-specific survey sections

\begin{tabular}{|c|c|c|c|}
\hline Course Topics & Numeracy & Ethics & Data Visualization \\
\hline Non-experimental designs & Rates \& rates of change & Confidentiality & $\begin{array}{l}\text { Advanced table design - } \\
\text { e.g., crosstabs, } \\
\text { contingency tables }\end{array}$ \\
\hline $\begin{array}{l}\text { Quasi-experimental } \\
\text { designs }\end{array}$ & $\begin{array}{l}\text { Percent \& percentage } \\
\text { point change }\end{array}$ & Honesty & Scatter plots \\
\hline Experimental designs & $\begin{array}{l}\text { Numerical relationships - } \\
\text { e.g., } 5 \text { times larger than } \mathrm{x}\end{array}$ & Objectivity & Box plots \\
\hline Qualitative methods & Order of operations & Plagiarism & Stem-and-leaf diagrams \\
\hline Sampling & Basic algebra & $\begin{array}{l}\text { Protection of human } \\
\text { subjects }\end{array}$ & Histograms \\
\hline Measurement & $\begin{array}{l}\text { Linear \& exponential } \\
\text { growth }\end{array}$ & Institutional review board & Time-series line graphs \\
\hline Descriptive statistics & Weighted averages & $\begin{array}{l}\text { Falsification of } \\
\text { data/results }\end{array}$ & Categorical bar graphs \\
\hline Probability - introduction & Aggregation of data & $\begin{array}{l}\text { Full disclosure of intent of } \\
\text { research to study subjects }\end{array}$ & Choropleth (shaded) maps \\
\hline $\begin{array}{l}\text { Probability distributions - } \\
\text { e.g., normal \& student's t }\end{array}$ & $\begin{array}{l}\text { Indexes e.g., Dow Jones, } \\
\text { CPI, BMI }\end{array}$ & $\begin{array}{l}\text { Full disclosure of any } \\
\text { conflicts of interest }\end{array}$ & Graduated symbol maps \\
\hline $\begin{array}{l}\text { Other probability } \\
\text { distributions - e.g., chi- } \\
\text { square }\end{array}$ & Probability, risk, odds & Data bias & Dot density maps \\
\hline Hypothesis testing & $\begin{array}{l}\text { Basic graphical } \\
\text { techniques }\end{array}$ & & \\
\hline \multicolumn{4}{|l|}{ Confidence intervals } \\
\hline \multicolumn{4}{|l|}{ Significance testing } \\
\hline \multicolumn{4}{|l|}{ Categorical data analysis } \\
\hline \multicolumn{4}{|l|}{ Correlation } \\
\hline \multicolumn{4}{|l|}{ Linear regression } \\
\hline \multicolumn{4}{|l|}{ Multiple regression } \\
\hline \multicolumn{4}{|l|}{$\begin{array}{l}\text { Nonlinear methods - e.g., } \\
\text { probit, logit }\end{array}$} \\
\hline Time-series analysis & & & \\
\hline
\end{tabular}


Tables 2a-e. Universal tables for 2013 vs. 2021 crosstabs.

Table 2a: National Survey on Teaching Research and Quantitative Methods--Cross-Tabulations for Numeracy Concepts

(marginal/statistical significance indicated by gray shading)

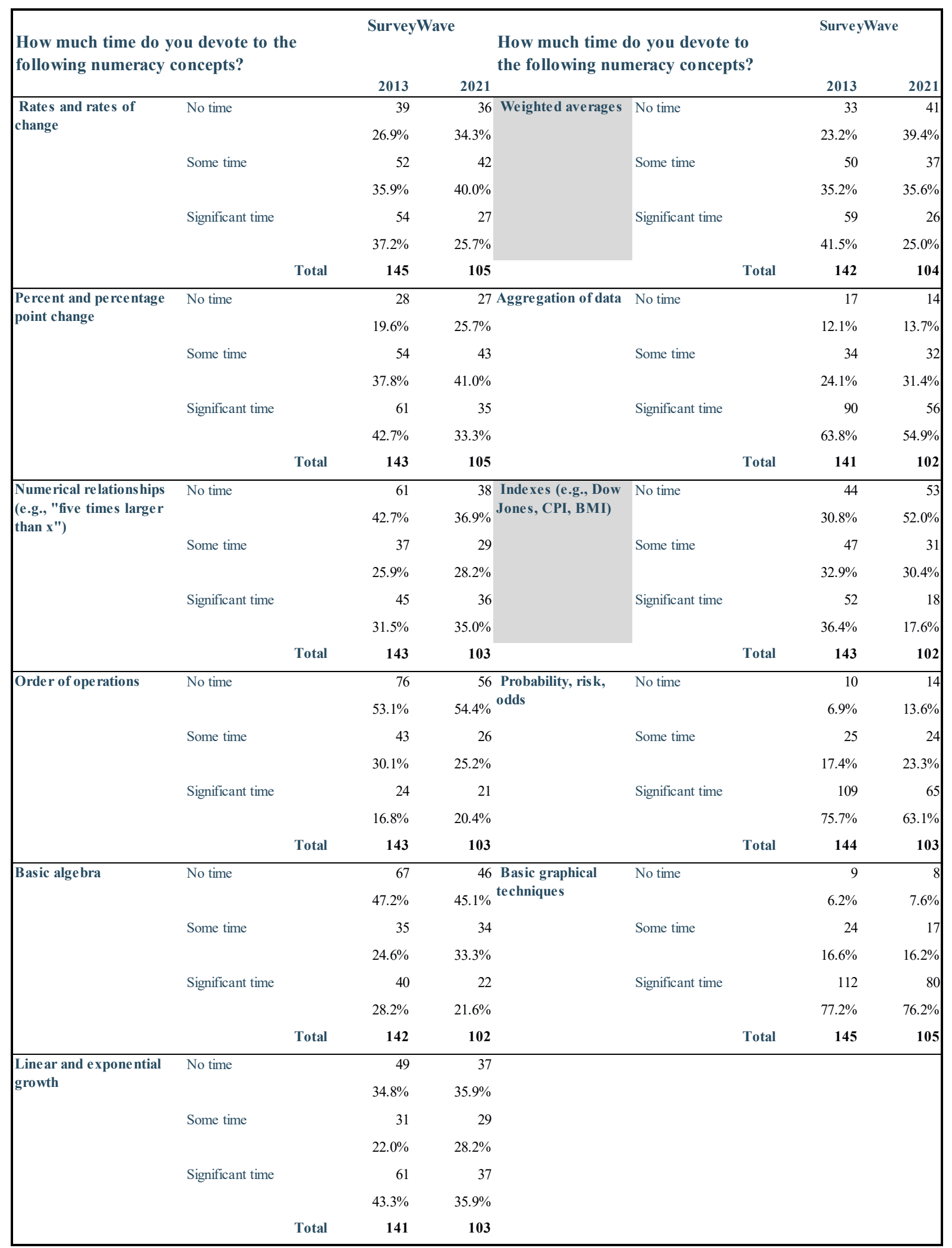


Table 2b: National Survey on Teaching Research and Quantitative Methods--Cross-Tabulations for Course Delivery Differences

(marginal/statistical significance indicated by gray shading)

\begin{tabular}{|c|c|c|c|c|}
\hline How has the counce offored throuch an & & & Survey & \\
\hline offered via traditional co urse delivery? & & & 2013 & 2021 \\
\hline Student inte raction & Less & & 11 & 52 \\
\hline & & & $31.4 \%$ & $57.1 \%$ \\
\hline & Same & & 13 & 32 \\
\hline & & & $37.1 \%$ & $35.2 \%$ \\
\hline & More & & 11 & 7 \\
\hline & & & $31.4 \%$ & $7.7 \%$ \\
\hline & & Total & 35 & 91 \\
\hline Computational exercises & Less & & 0 & 12 \\
\hline & & & $0.0 \%$ & $13.6 \%$ \\
\hline & Same & & 29 & 64 \\
\hline & & & $82.9 \%$ & $72.7 \%$ \\
\hline & More & & 6 & 12 \\
\hline & & & $17.1 \%$ & $13.6 \%$ \\
\hline & & Total & 35 & $\mathbf{8 8}$ \\
\hline Ins tructor feedback on student progress & Less & & 0 & 7 \\
\hline & & & $0.0 \%$ & $7.7 \%$ \\
\hline & Same & & 19 & 58 \\
\hline & & & $54.3 \%$ & $63.7 \%$ \\
\hline & More & & 16 & 26 \\
\hline & & & $45.7 \%$ & $28.6 \%$ \\
\hline & & Total & 35 & 91 \\
\hline Instructor time spent in preparation & Less & & 2 & 4 \\
\hline & & & $5.6 \%$ & $4.4 \%$ \\
\hline & Same & & 12 & 29 \\
\hline & & & $33.3 \%$ & $31.9 \%$ \\
\hline & More & & 22 & 58 \\
\hline & & & $61.1 \%$ & $63.7 \%$ \\
\hline & & Total & 36 & 91 \\
\hline Instructor time spent grading & Less & & 0 & 5 \\
\hline & & & $0.0 \%$ & $5.5 \%$ \\
\hline & Same & & 18 & 55 \\
\hline & & & $51.4 \%$ & $60.4 \%$ \\
\hline & More & & 17 & 31 \\
\hline & & & $48.6 \%$ & $34.1 \%$ \\
\hline & & Total & 35 & 91 \\
\hline Overall class attainment of le arning objectives & Less & & 2 & 17 \\
\hline & & & $5.9 \%$ & $18.7 \%$ \\
\hline & Same & & 24 & 58 \\
\hline & & & $70.6 \%$ & $63.7 \%$ \\
\hline & More & & 8 & 16 \\
\hline & & & $23.5 \%$ & $17.6 \%$ \\
\hline & & Total & 34 & 91 \\
\hline
\end{tabular}


Table 2c: National Survey on Teaching Research and Quantitative Methods--Cross-Tabulations for Course Topical Coverage (margina/statistical significance indicated by gray shading)

\begin{tabular}{|c|c|c|c|c|c|c|c|c|c|}
\hline \multicolumn{2}{|c|}{$\begin{array}{c}\text { What are the main topics covered by } \\
\text { your quantitative and research } \\
\text { methods course? }\end{array}$} & SurveyWave & \multicolumn{2}{|c|}{$\begin{array}{c}\text { What are the main topics covered by } \\
\text { your quantitative and research } \\
\text { methods course? }\end{array}$} & SurveyWave & \multicolumn{2}{|c|}{$\begin{array}{l}\text { What are the main topics covered by } \\
\text { your quantitative and research } \\
\text { methods course? }\end{array}$} & \multicolumn{2}{|c|}{ SurveyWave } \\
\hline \multirow[t]{7}{*}{$\begin{array}{l}\text { Non-experimental } \\
\text { designs }\end{array}$} & $\begin{array}{l}\text { Less than one hour } \\
\text { (lecture and exercise) }\end{array}$ & 53 & 29 Probability-Intro & $\begin{array}{l}\text { Less than one hour } \\
\text { (lecture and exercise) }\end{array}$ & 54 & 49 Correlation & $\begin{array}{l}\text { Less than one hour } \\
\text { (lecture and exercise) }\end{array}$ & 31 & 25 \\
\hline & & $38.4 \%$ & $28.2 \%$ & & $38.6 \%$ & $46.2 \%$ & & $22.0 \%$ & $23.6 \%$ \\
\hline & One to two hours & 33 & 27 & One to two hours & 32 & 22 & One to two hours & 40 & 39 \\
\hline & & $23.9 \%$ & $26.2 \%$ & & $22.9 \%$ & $20.8 \%$ & & $28.4 \%$ & $36.8 \%$ \\
\hline & Two or more hours & 52 & 47 & Two or more hours & 54 & 35 & Two or more hours & 70 & 42 \\
\hline & (lecture and exercise) & $37.7 \%$ & $45.6 \%$ & & $38.6 \%$ & $33.0 \%$ & & $49.6 \%$ & $39.6 \%$ \\
\hline & Total & 138 & 103 & Total & 140 & 106 & Total & 141 & 106 \\
\hline \multirow[t]{7}{*}{$\begin{array}{l}\text { Quasi-e xpe rimental } \\
\text { designs }\end{array}$} & $\begin{array}{l}\text { Less than one hour } \\
\text { (lecture and exercise) }\end{array}$ & 44 & $\begin{array}{l}46 \text { Probability distribution } \\
\text { (normal and student's } t\end{array}$ & $\begin{array}{l}\text { Less than one hour } \\
\text { (lecture and exercise) }\end{array}$ & 39 & 38 Linear regression & $\begin{array}{l}\text { Less than one hour } \\
\text { (lecture and exercise) }\end{array}$ & 12 & 11 \\
\hline & & $31.2 \%$ & $44.2 \%$ & & $27.9 \%$ & $35.8 \%$ & & $8.5 \%$ & $10.4 \%$ \\
\hline & One to two hours & 44 & 31 & One to two hours & 28 & 31 & One to two hours & 17 & 11 \\
\hline & & $31.2 \%$ & $29.8 \%$ & & $20.0 \%$ & $29.2 \%$ & & $12.1 \%$ & $10.4 \%$ \\
\hline & Two or more hours & 53 & 27 & Two or more hours & 73 & 37 & Two or more hours & 22 & 20 \\
\hline & & $37.6 \%$ & $26.0 \%$ & & $52.1 \%$ & $34.9 \%$ & & $15.6 \%$ & $18.9 \%$ \\
\hline & Total & 141 & 104 & Total & 140 & 106 & Total & 141 & 106 \\
\hline \multirow[t]{7}{*}{ Experimental designs } & $\begin{array}{l}\text { Less than one hour } \\
\text { (lecture and exercise) }\end{array}$ & 49 & $\begin{array}{l}39 \text { Other probability } \\
\text { distributions (chi- }\end{array}$ & $\begin{array}{l}\text { Less than one hour } \\
\text { (lecture and exercise) }\end{array}$ & 47 & 40 Multiple regression & $\begin{array}{l}\text { Less than one hour } \\
\text { (lecture and exercise) }\end{array}$ & 29 & 22 \\
\hline & & $35.0 \%$ & $37.5 \%$ square, etc.) & & $34.1 \%$ & $38.1 \%$ & & $20.6 \%$ & $20.8 \%$ \\
\hline & One to two hours & 40 & 37 & One to two hours & 30 & 31 & One to two hours & 22 & 20 \\
\hline & & $28.6 \%$ & $35.6 \%$ & & $21.7 \%$ & $29.5 \%$ & & $15.6 \%$ & $18.9 \%$ \\
\hline & Two or more hours & 51 & 28 & Two or more hours & 61 & 34 & Two or more hours & 90 & 64 \\
\hline & & $36.4 \%$ & $26.9 \%$ & & $44.2 \%$ & $32.4 \%$ & & $63.8 \%$ & $60.4 \%$ \\
\hline & Total & 140 & 104 & Total & 138 & 105 & Total & 138 & 106 \\
\hline \multirow[t]{7}{*}{ Qualitative methods } & $\begin{array}{l}\text { Less than one hour } \\
\text { (lecture and exercise) }\end{array}$ & 57 & 53 Hypothesis testing & $\begin{array}{l}\text { Less than one hour } \\
\text { (lecture and exercise) }\end{array}$ & 21 & $\begin{array}{l}20 \text { Nonlinear me thods } \\
\text { (Probit, Logit, etc.) }\end{array}$ & $\begin{array}{l}\text { Less than one hour } \\
\text { (lecture and exercise) }\end{array}$ & 101 & 75 \\
\hline & & $40.7 \%$ & $51.0 \%$ & & $14.9 \%$ & $18.9 \%$ & & $74.3 \%$ & $71.4 \%$ \\
\hline & One to two hours & 22 & 16 & One to two hours & 26 & 25 & One to two hours & 15 & 13 \\
\hline & & $15.7 \%$ & $15.4 \%$ & & $18.4 \%$ & $23.6 \%$ & & $11.0 \%$ & $12.4 \%$ \\
\hline & Two or more hours & 61 & 35 & Two or more hours & 94 & 61 & Two or more hours & 20 & 17 \\
\hline & & $43.6 \%$ & $33.7 \%$ & & $66.7 \%$ & $57.5 \%$ & & $14.7 \%$ & $16.2 \%$ \\
\hline & Total & 140 & 104 & Total & 141 & 106 & Total & 136 & 105 \\
\hline \multirow[t]{7}{*}{ Sampling } & $\begin{array}{l}\text { Less than one hour } \\
\text { (lecture and exercise) }\end{array}$ & 32 & 26 Confidence intervals & $\begin{array}{l}\text { Less than one hour } \\
\text { (lecture and exercise) }\end{array}$ & 34 & 41 Time series analysis & $\begin{array}{l}\text { Less than one hour } \\
\text { (lecture and exercise) }\end{array}$ & 109 & 89 \\
\hline & & $22.5 \%$ & $24.8 \%$ & & $24.5 \%$ & $39.0 \%$ & & $79.0 \%$ & $84.8 \%$ \\
\hline & One to two hours & 50 & 33 & One to two hours & 42 & 28 & One to two hours & 14 & 10 \\
\hline & & $35.2 \%$ & $31.4 \%$ & & $30.2 \%$ & $26.7 \%$ & & $10.1 \%$ & $9.5 \%$ \\
\hline & Two or more hours & 60 & 46 & Two or more hours & 63 & 36 & Two or more hours & 15 & \\
\hline & & $42.3 \%$ & $43.8 \%$ & & $45.3 \%$ & $34.3 \%$ & & $10.9 \%$ & $5.7 \%$ \\
\hline & Total & 142 & 105 & Total & 139 & 105 & Total & 138 & 105 \\
\hline \multirow[t]{7}{*}{ Measurement } & $\begin{array}{l}\text { Less than one hour } \\
\text { (lecture and exercise) }\end{array}$ & 17 & 20 Significance testing & $\begin{array}{l}\text { Less than one hour } \\
\text { (lecture and exercise) }\end{array}$ & 24 & 25 & & & \\
\hline & & $12.1 \%$ & $18.9 \%$ & & $17.0 \%$ & $23.6 \%$ & & & \\
\hline & One to two hours & 49 & 28 & One to two hours & 28 & 25 & & & \\
\hline & & $34.8 \%$ & $26.4 \%$ & & $19.9 \%$ & $23.6 \%$ & & & \\
\hline & Two or more hours & 75 & 58 & Two or more hours & 89 & 56 & & & \\
\hline & & $53.2 \%$ & $54.7 \%$ & & $63.1 \%$ & $52.8 \%$ & & & \\
\hline & Total & 141 & 106 & Total & 141 & 106 & & & \\
\hline \multirow[t]{7}{*}{ Descriptive statistics } & $\begin{array}{l}\text { Less than one hour } \\
\text { (lecture and exercise) }\end{array}$ & 17 & $\begin{array}{l}17 \text { Categorical data } \\
\text { analysis }\end{array}$ & $\begin{array}{l}\text { Less than one hour } \\
\text { (lecture and exercise) }\end{array}$ & 35 & 29 & & & \\
\hline & & $12.1 \%$ & $16.0 \%$ & & $25.2 \%$ & $27.6 \%$ & & & \\
\hline & One to two hours & 26 & 21 & One to two hours & 40 & 28 & & & \\
\hline & & $18.4 \%$ & $19.8 \%$ & & $28.8 \%$ & $26.7 \%$ & & & \\
\hline & Two or more hours & 98 & 68 & Two or more hours & 64 & 48 & & & \\
\hline & & $69.5 \%$ & $64.2 \%$ & & $46.0 \%$ & $45.7 \%$ & & & \\
\hline & Total & 141 & 106 & Total & 139 & 105 & & & \\
\hline
\end{tabular}


Table 2d: National Survey on Teaching Research and Quantitative Methods-Cross-Tabulations for Ethical Concepts and Principles

(marginal/statistical significance indicated by gray shading)

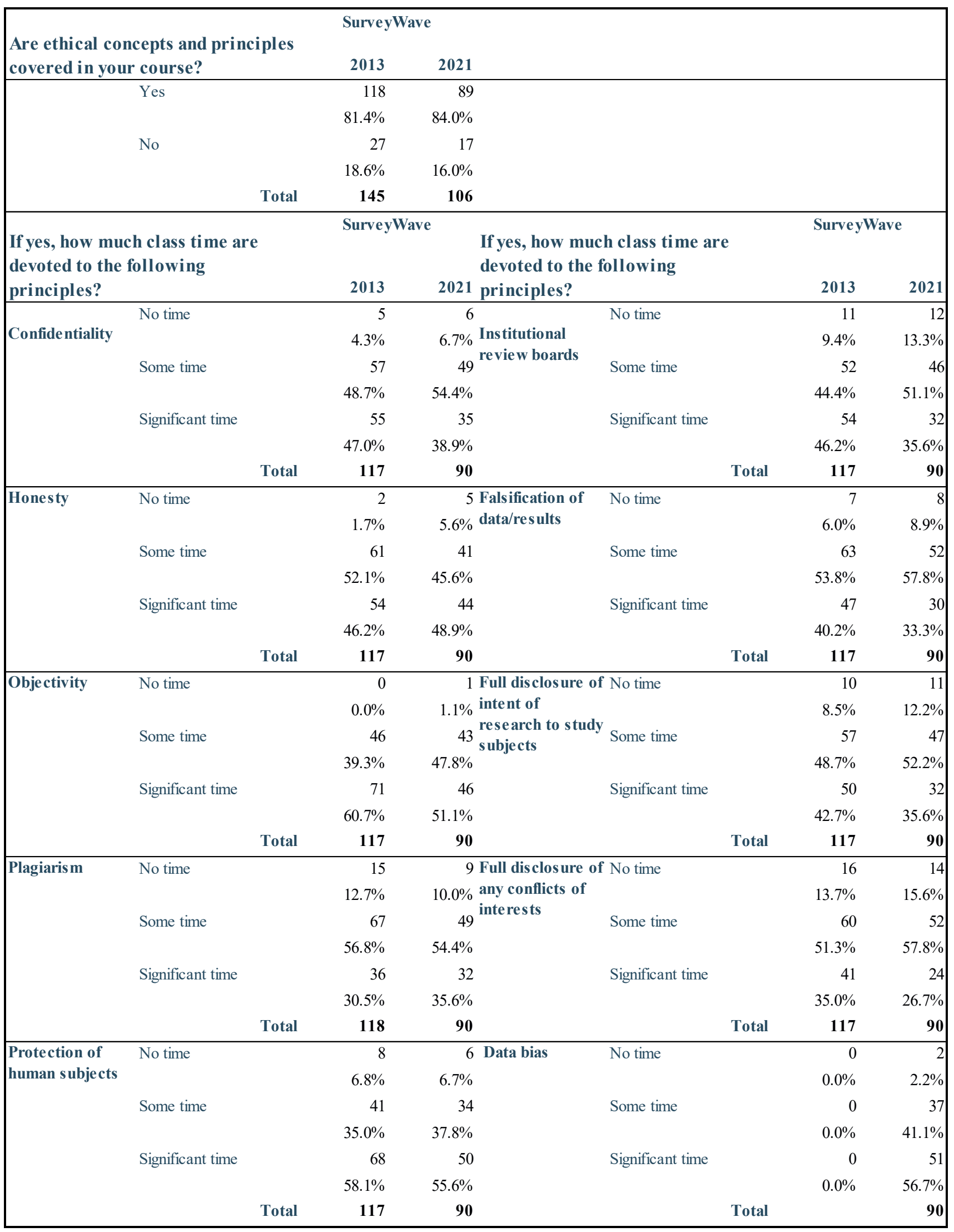


Table 2e: National Survey on Teaching Research and Quantitative Methods--Cross-Tabulations for Data Visualization Techniques

(marginal/statistical significance indicated by gray shading)

\begin{tabular}{|c|c|c|c|c|c|c|c|}
\hline $\begin{array}{l}\text { How much time to } \\
\text { following data visual }\end{array}$ & $\begin{array}{l}\text { you devote to the } \\
\text { zation techniques? }\end{array}$ & Survey & & $\begin{array}{l}\text { How much time to } \\
\text { following data visual }\end{array}$ & $\begin{array}{l}\text { you devote to the } \\
\text { ization techniques? }\end{array}$ & Survey & \\
\hline Advanced table design & & $13.5 \%$ & $16.3 \%$ & Time-series line graphs & & $25.4 \%$ & $33.3 \%$ \\
\hline (cross-tabs, continge ncy & Some time & 32 & 13 & & Some time & 55 & 35 \\
\hline & & $62.4 \%$ & $71.2 \%$ & & & $33.6 \%$ & $33.3 \%$ \\
\hline & Total & 133 & 104 & & Total & 134 & 105 \\
\hline Scatter plots & No time & 15 & 14 & Categorical bar graphs & No time & 16 & 21 \\
\hline & & $11.3 \%$ & $13.2 \%$ & & & $12.0 \%$ & $20.0 \%$ \\
\hline & Some time & 41 & 31 & & Some time & 54 & 33 \\
\hline & Total & 133 & 106 & & Total & 133 & 105 \\
\hline Box plots & No time & 43 & 47 & Chorople th (s haded) & No time & 102 & 88 \\
\hline & & $32.8 \%$ & $44.8 \%$ & maps & & $78.5 \%$ & $83.8 \%$ \\
\hline & Some time & 45 & 30 & & Some time & 23 & 12 \\
\hline & & $34.4 \%$ & $28.6 \%$ & & & $17.7 \%$ & $11.4 \%$ \\
\hline & Significant time & 43 & 28 & & Significant time & 5 & 5 \\
\hline & & $32.8 \%$ & $26.7 \%$ & & & $3.8 \%$ & $4.8 \%$ \\
\hline & Total & 131 & 105 & & Total & 130 & 105 \\
\hline Stem-and-le af diagrams & No time & 57 & 71 & Graduated symbol maps & No time & 106 & 95 \\
\hline & & $43.8 \%$ & $67.0 \%$ & & & $80.3 \%$ & $90.5 \%$ \\
\hline & & $4.5 \%$ & $15.1 \%$ & & & $75.4 \%$ & $83.0 \%$ \\
\hline & Some time & 52 & 37 & & Some time & 25 & 9 \\
\hline & & $38.8 \%$ & $34.9 \%$ & & & $19.2 \%$ & $8.5 \%$ \\
\hline & Significant time & 76 & 53 & & Significant time & 7 & 9 \\
\hline & & $56.7 \%$ & $50.0 \%$ & & & $5.4 \%$ & $8.5 \%$ \\
\hline & Total & 134 & 106 & & Total & 130 & 106 \\
\hline
\end{tabular}


Table 3: Effects of COVID-19 on Course Content--Cross-Tabulations

(only statistically significant findings presented)

\begin{tabular}{|c|c|c|c|c|c|c|c|c|c|}
\hline \multicolumn{3}{|c|}{$\begin{array}{l}\text { How much time do you devote to the } \\
\text { following concepts? }\end{array}$} & \multicolumn{2}{|c|}{ Mention COVID-19 } & \multicolumn{3}{|c|}{$\begin{array}{l}\text { How much time do you devote to } \\
\text { the following concepts? }\end{array}$} & \multicolumn{2}{|c|}{ Mention COVID-19 } \\
\hline & & & No & Yes & & & & No & Yes \\
\hline \multirow[t]{7}{*}{ Aggregation of Data } & No time & & 6 & & 8 Correlations & No time & & 10 & 15 \\
\hline & & & $9.4 \%$ & $21.1 \%$ & & & & $14.9 \%$ & $38.5 \%$ \\
\hline & Some time & & 18 & 14 & & Some time & & 28 & 11 \\
\hline & & & $28.1 \%$ & $36.8 \%$ & & & & $41.8 \%$ & $28.2 \%$ \\
\hline & Significant time & & 40 & 16 & & Significant time & & 29 & 13 \\
\hline & & & $62.5 \%$ & $42.1 \%$ & & & & $43.3 \%$ & $33.3 \%$ \\
\hline & & Total & 64 & 38 & & & Total & 67 & 39 \\
\hline \multirow{7}{*}{$\begin{array}{l}\text { Indexes (e.g., Dow Jones, } \\
\text { CPI, BMI) }\end{array}$} & No time & & 28 & & 5 Linear Regression & No time & & 9 & 13 \\
\hline & & & $43.8 \%$ & $65.8 \%$ & & & & $13.4 \%$ & $33.3 \%$ \\
\hline & Some time & & 22 & 9 & 9 & Some time & & 16 & 4 \\
\hline & & & $34.4 \%$ & $23.7 \%$ & & & & $23.9 \%$ & $10.3 \%$ \\
\hline & Significant time & & 14 & 4 & 4 & Significant time & & 42 & 22 \\
\hline & & & $21.9 \%$ & $10.5 \%$ & & & & $62.7 \%$ & $56.4 \%$ \\
\hline & & Total & 64 & 38 & & & Total & 67 & 39 \\
\hline \multirow[t]{7}{*}{ Qualitative Methods } & No time & & 28 & 25 & 5 Multiple Regression & No time & & 9 & 15 \\
\hline & & & $43.1 \%$ & $64.1 \%$ & & & & $13.4 \%$ & $38.5 \%$ \\
\hline & Some time & & 13 & 3 & 3 & Some time & & 18 & 5 \\
\hline & & & $20.0 \%$ & $7.7 \%$ & & & & $26.9 \%$ & $12.8 \%$ \\
\hline & Significant time & & 24 & 11 & & Significant time & & 40 & 19 \\
\hline & & & $36.9 \%$ & $28.2 \%$ & & & & $59.7 \%$ & $48.7 \%$ \\
\hline & & Total & 65 & 39 & & & Total & 67 & 39 \\
\hline \multirow[t]{7}{*}{ Sampling } & No time & & 11 & & 5 Honesty & No time & & 1 & 4 \\
\hline & & & $16.7 \%$ & $38.5 \%$ & & & & $1.7 \%$ & $12.5 \%$ \\
\hline & Some time & & 25 & 8 & 8 & Some time & & 27 & 14 \\
\hline & & & $37.9 \%$ & $20.5 \%$ & & & & $46.6 \%$ & $43.8 \%$ \\
\hline & Significant time & & 30 & 16 & & Significant time & & 30 & 14 \\
\hline & & & $45.5 \%$ & $41.0 \%$ & & & & $51.7 \%$ & $43.8 \%$ \\
\hline & & Total & 66 & 39 & & & Total & 58 & 32 \\
\hline \multirow[t]{7}{*}{ Descriptive Statistics } & No time & & 6 & & 1 Plagiaris m & No time & & 4 & 5 \\
\hline & & & $9.0 \%$ & $28.2 \%$ & & & & $6.9 \%$ & $15.6 \%$ \\
\hline & Some time & & 16 & 5 & 5 & Some time & & 28 & 21 \\
\hline & & & $23.9 \%$ & $12.8 \%$ & & & & $48.3 \%$ & $65.6 \%$ \\
\hline & Significant time & & 45 & 23 & & Significant time & & 26 & 6 \\
\hline & & & $67.2 \%$ & $59.0 \%$ & & & & $44.8 \%$ & $18.8 \%$ \\
\hline & & Total & 67 & 39 & & & Total & 58 & 32 \\
\hline \multirow[t]{7}{*}{ Probability Dis tributions } & No time & & 19 & & 9 Time-Series Line & No time & & 18 & 17 \\
\hline & & & $28.4 \%$ & $48.7 \%$ & Gr: & & & $26.5 \%$ & $45.9 \%$ \\
\hline & Some time & & 23 & 8 & 8 & Some time & & 27 & 8 \\
\hline & & & $34.3 \%$ & $20.5 \%$ & & & & $39.7 \%$ & $21.6 \%$ \\
\hline & Significant time & & 25 & 12 & & Significant time & & 23 & 12 \\
\hline & & & $37.3 \%$ & $30.8 \%$ & & & & $33.8 \%$ & $32.4 \%$ \\
\hline & & Total & 67 & 39 & & & Total & 68 & 37 \\
\hline \multirow[t]{7}{*}{ Hypothesis Testing } & No time & & 9 & 11 & & & & & \\
\hline & & & $13.4 \%$ & $28.2 \%$ & & & & & \\
\hline & Some time & & 14 & 11 & & & & & \\
\hline & & & $20.9 \%$ & $28.2 \%$ & & & & & \\
\hline & Significant time & & 44 & 17 & & & & & \\
\hline & & & $65.7 \%$ & $43.6 \%$ & & & & & \\
\hline & & Total & 67 & 39 & & & & & \\
\hline
\end{tabular}

